\title{
EI Juicio de Amparo como garante del Estado de Derecho en México
}

\author{
Arturo Hernández Segovia \\ Doctor en Derecho Público, Universidad Veracruzana \\ Maestro en Derecho Constitucional y Amparo, Universidad Autónoma de Tlaxcala \\ Licenciado en Derecho, Universidad Veracruzana, México \\ E-mail: segovia_art@hotmial.com
}

Resumen

En México el juicio de amparo es el instrumento idóneo a través del cual el gobernado obtiene justicia cuando las autoridades (jurisdiccionales o administrativas) en su actuar violentan sus derechos fundamentales; actualmente el legislador insertó en el derecho de amparo nuevas figuras jurídicas con las que se pretende mejorar a tal institución, por lo que este mecanismo de control constitucional indudablemente resulta ser el medio eficaz para que impereun Estado de Derecho en pro de la persona.

Palabras clave: Derecho de Amparo, Derechos fundamentales, Control constitucional.

\begin{abstract}
In Mexico the injunction is the appropriate instrument through which the governed get justice when authorities (judicial or administrative) in his actions violate their fundamental rights; currently the legislature inserted into the new legal right under figures that aims to improve such an institution, so this mechanism is undoubtedly constitutional control provide effective means for the rule of law prevails towards the person.
\end{abstract}

Keywords: Law of Amparo, Fundamental rights, Constitutional control.

\section{Résumé}

Au Mexique l'injonction est l'instrument approprié par lequel la justice get régie lorsque les autorités (judiciaires ou administratives) dans ses actions portent atteinte à leurs droits fondamentaux; actuellement le législateur a inséré, dans le nouveau droit, en vertu des chiffres qui vise à améliorer une telle institution, si ce mécanisme est sans aucun doute le contrôle constitutionnel fournir des moyens efficaces pour la primauté du droit à la personne.

Mots-clés: Droit de Amparo, Les droits fondamentaux, Le contrôle constitutionnel. 



\section{EI Juicio de Amparo como garante del Estado de Derecho en México}

Arturo Hernández Segovia

\section{INTRODUCCIÓN}

En el mes de abril de 2013 en México, entró en vigor una nueva Ley de Amparo donde si bien siguen permeando figuras jurídicas ya contempladas en la anterior ley de 1936, lo cierto es que también se incorporan otras que permiten aproximarnosal ideal máximo del derecho que es la justicia.

Ciertamente, en esta nueva ley se prevé la apariencia del buen derecho para otorgar la suspensión, el amparo adhesivo en lo tocante al amparo directo, el interés legítimo tratándose del amparo contra actos administrativos, se contemplan nuevos supuestos de suplencia de la deficiencia de la queja, entre otros.

Sin embargo, para poder hablar de estas innovaciones se considera indispensable puntualizar que la figura del amparo considerado como un medio de control constitucional que opera contra actos, omisiones o normas generales emitidos por una autoridad que trastocan los derechos humanos de las personas, es un juicio cuyo fundamento lo encontramos en los Artículos 103 y 107 de la Constitución Política de los Estados Unidos Mexicanos, es decir, es un juicio diseñado exclusivamente para tutelar los derechos humanos del gobernado.

Efectivamente, el amparo resulta ser un juicio, y por tanto, existe una parte actora, una parte demanda, una litis, pruebas, alegatos, y una Sentencia, del que conocen órganos jurisdiccionales especializados en la materia de amparo.

Lo anterior se aprecia así del precitado numeral 103, de la Constitución Federal, que dice:

Los Tribunales de la Federación resolverán toda controversia que se suscite:

I.- Por normas generales, actos u omisiones de la autoridad que violenten los derechos humanos reconocidos y las garantías otorgadas para su protección por esta Constitución, así como por los tratados internacionales de los que el Estado mexicano sea parte; 
II.- Por nomas generales o actos de la autoridad federal que vulneren o restrinjan la soberanía de los Estados o la esfera de competencia del Distrito Federal; y

III.- Por normas generales o actos de las autoridades de los Estados o del Distrito Federal que invadan la esfera de competencia de la autoridad federal.

Del precepto reproducido, se obtiene que sean los tribunales de la federación quienes conozcan de los juicios de amparo, mismos que se hacen consistir por orden jerárquico en los siguientes:

i).- Suprema Corte de Justicia de la Nación.

ii).- Tribunales Colegiados de Circuito.

iii).- Tribunales Unitarios de Circuito.

iv).- Juzgados de Distrito.

La Suprema Corte de Justicia de la Nación -máximo tribunal del país integrado por once ministros- conocerá del juicio de amparo directo de manera excepcional, esto es, al ejercer la facultad de atracción por considerar que el asunto reviste importancia y trascendencia que puede ser política, social o económica, a nivel nacional; de otra forma, los órganos competentes para conocer del juicio en cita, por regla general, serán los Tribunales Colegiados de Circuito.

Los Tribunales Colegiados de Circuito, como ya se anticipó, son los órganos que por mandato de la ley reglamentaria de los Artículos 103 y 107 de la Constitución Política de los Estados Unidos Mexicanos, deben de conocer del juicio de amparo directo o uni-instancial, donde cada Tribunal Colegiado se integra por tres magistrados, un secretario de acuerdos, y de la cantidad de secretarios, actuarios y empleados necesarios para el despacho de los juicios de amparo directo.

Los Tribunales Unitarios de Circuito, son aquellos que - de manera excepcionalconocen del juicio de amparo indirecto o bi-instancial, dado que son tribunales de segunda instancia en el procedimiento ordinario federal, esto es, conocen de la apelación interpuesta contra el fallo de su inferior, por lo que únicamente serán competentes para conocer de este juicio de amparo indirecto cuando el acto de autoridad que violente los derechos humanos de la persona sea cometido por otro Tribunal Unitario de Circuito,que resulta ser de la misma jerarquía, pues los órganos jurisdiccionales que deben conocer de este tipo de amparo "indirecto", por regla general,son los Juzgados de Distrito.

Cada uno de los Tribunales Unitarios de Circuito se integra por un magistrado y la cantidad de secretarios, actuarios y empleados necesarios para el despacho de los asuntos. 
Finalmente, los Juzgados de Distrito son los órganos facultados para conocer del juicio de amparo indirecto o bi-instancial, tales órganos se componen de un juez y de la cantidad de secretarios, actuarios y empleados necesarios para la resolución de los juicios de su competencia.

Significando que actualmente en México existen 201 Tribunales Colegiados de Circuito, 81 Tribunales Unitarios de Circuito y 331 Juzgados de Distrito1.

Ahora bien -como ya se destacó-el juicio de amparo se divide en indirecto o biinstancial y directo o uni-instancial.

Esta dicotomía descansa en las hipótesis de procedencia, aunque no debe soslayarse que -en ambos- la teleología del juicio es la de proteger los derechos humanos frente a los actos de la autoridad que los trastoquen.

\section{PROCEDENCIA DEL JUICIO DE AMPARO INDIRECTO}

El juicio de amparo indirecto o bi-instancial, conforme a lo dispuesto por el Artículo 107 de la Ley de Amparo, procede en los siguientes supuestos:

(I) Contra normas generales, por considerar que trastocan los derechos humanos reconocidos en la Constitución Federal como en los tratados internacionales donde México sea un Estado parte.

Aquí se tienen que hacer la precisión, de que si con motivo de la entrada en vigor de tal norma general, es que se causa una afectación en la esfera jurídica del gobernado, estamos frente a una norma auto-aplicativa.

Mientras que si la afectación en los derechos humanos de lo gobernado deriva, no de la entrada en vigor de la norma, sino del primer acto de aplicación, esto es, que para que se causeun agravio en los derechos esenciales del gobernado, se requiere que la norma se aplique, nos hallamos en presencia de una norma hetero-aplicativa.

(II) Contra actos administrativos.

En esta hipótesis el juicio de amparo indirecto procede contra todo acto de índole administrativa, por considerar que trastocan los derechos básicos del gobernado.

Se califican a estos actos como administrativos, en razón de ser emitidos por una autoridad de naturaleza administrativa y no de índole jurisdiccional.

(III) Contra actos, omisiones o resoluciones que provengan de un procedimiento administrativo -seguido en forma de juicio-siempre que se trate de la resolución que le pongan fin a ese procedimiento, o bien, que se impugne una actuación dentro del referido procedimiento, siempre que sea de imposible reparación, es decir, que dicho acto afecte materialmente derechos sustantivos tutelados en la Constitución Federal y en los tratados internacionales de los que el Estado Mexicano sea parte,

1. Disponible en: http://www.dgepj.cjf.gob.mx 
no susceptible de repararse con el dictado de la resolución administrativa que le pone fin a tal procedimiento.

Se precisa que -en este supuesto- se alude a un procedimiento administrativo seguido en forma de juicio, dado que ello no es propiamente un juicio al ser substanciado por una autoridad estrictamente administrativa no jurisdiccional, sin embargo en tal procedimiento se le respeta al gobernado su derecho de audiencia para que manifieste lo que considere pertinente, así como la oportunidad de ofrecer pruebas para soportar sus asertos; de ahí que se califique como un procedimiento seguido en forma de juicio.

(IV) Contra actos emitidos por tribunales (judiciales, administrativos, agrarios, o de trabajo), que se hayan realizado fuera de juicio o después de concluido.

Esta hipótesis habla de dos momentos.

El primero se refiere a que el juicio de amparo indirecto procederá cuando el acto reclamado sea una actuación pronunciada fuera de juicio, esto es, que dicho acto reclamado en la vía de amparo, se haya emitido por el órgano jurisdiccional antes de iniciarse el juicio.

Por ejemplo, un acto emitido fuera de juicio -susceptible de impugnarse en el amparo indirecto- lo sería la falta de notificación a los unos medios preparatorios a juicio, ya que el desconocimiento de tales diligencias daría lugar a que se deje sin defensa al quejoso ante tales diligencias previas.

El segundo, alude a que el juicio de amparo indirecto procederá cuando el acto reclamado se haya emitido después de concluido el juicio.

Un ejemplo lo sería, si el acto reclamado se hace consistir en la interlocutoria que decide el incidente de nulidad de actuaciones intentado contra la ilegal notificación de la Sentencia, pues dicha resolución incidental es una actuación que califica una notificación practicada después de que concluyó el juicio.

Aquí es necesario puntualizar, que tratándose de actos emitidos en la etapa de ejecución de una Sentencia -los cuales también resultan seractuaciones dictadas una vez concluido el juicio- el amparo indirecto sólo procederá contra la última resolución dictada en el procedimiento aludido, entendiendo por última resolución como aquella que aprueba o reconoce el cumplimiento total de la Sentencia, o bien declara la imposibilidad material o jurídica para darle cumplimiento.

(V) Contra actos dictados dentro de juicio.

El juicio de amparo indirecto procederá contra actuaciones emitidas por el juez durante la substanciación del juicio, siempre y cuando tal actuación sea de imposible reparación.

Entendiéndose por actos de imposible reparación, los que afectan materialmente y de forma directa, derechos básicos o esenciales tutelados por la Constitución Política de los Estados Unidos Mexicanos, así como en los tratados internacionales en los que México sea un Estado parte, mismos que no son susceptibles de repararse con el dictado de la Sentencia. 
(VI) Cuando el acto reclamado dictado dentro o fuera de juicio, afecte a personas extrañas al juicio.

Precisándose que por persona extraña a juicio, debe entenderse como aquella que, teniendo interés en el negocio que se litiga en el juicio natural, no fue señalada como parte demandada.

Asimismo, se prevé la figura de persona extra a juicio por equiparación, la cual es aquella que siendo señalada como parte demandada en el juicio natural, fue incorrecta o ilegalmente emplazada al juicio.

Por tanto, en ambos casos la parte demandada desconoce la existencia del juicio de origen, ya sea porque no se le señaló como parte demandada o bien, porque aun llamándole como tal, fue mal emplazada al juicio, y es por tal evento que se le denomina como persona extraña al juicio o persona extraña al juicio por equiparación.

(VII) Contra las omisiones del Ministerio Público en la investigación de los delitos, como sería no darle curso a la querella interpuesta por la víctima.

Así como también, contras las resoluciones de reserva emitidas por el Ministerio Púbico, dado que ello trastoca la seguridad jurídica tanto del acusado como de la víctima, en razón de que la indagatoria queda suspendida hasta en tanto aparezcan más pruebas o datos que esclarezcan los hechos ilícitos que se reprochan.

De igual forma, procede el amparo indirecto contra la determinación del Ministerio Público sobre el no ejercicio de la acción penal, el desistimiento de la acción persecutoria, o por la suspensión del procedimiento cuando no esté satisfecha la reparación del daño.

(VIII) Contra actos de la autoridad que determine inhibir o declinar la competencia o el conocimiento de un asunto.

Aquí hay que puntualizar que la procedencia del amparo indirecto estriba en el hecho de que carecería de todo valor jurídico una determinación emitida por una autoridad que resulte incompetente, de ahí la trascendencia de su análisis a través del amparo bi-instancial.

\section{SUBSTANCIACIÓN DEL JUICIO DE AMPARO INDIRECTO}

La demanda de amparo deberá de presentarse ante el Juez de Distrito en el término de quince días contados a partir del día siguiente al en que surte efecto la notificación del acto que se reclama, conforme a la ley que rige dicho acto que se estima inconstitucional, o bien al día siguiente en que se tiene conocimiento o es sabedor del mencionado acto.

El Juez de Distrito en el término de veinticuatro días a partir de la presentación de la demanda, deberá acordar sobre si desecha la demanda por actualizarse alguna causal de improcedencia, si previene al quejoso para que subsane alguna irregularidad advertida, o bien, admita la misma. 
De darse el último supuesto, esto es, que se admita la demanda de amparo, el Juez de Distrito en ese mismo acuerdo, señalará día y hora para la celebración de la audiencia, que se desahogará dentrodel término de treinta días siguientes, asimismo pedirá que la autoridad responsable rinda su informe con justificacióny ordenará correr traslado al tercero interesado.

Notificada la autoridad responsable del anterior proveído, deberá rendir su informe con justificación -que hace las veces de contestación a la demanda de amparo- dentro del término de quince días.

En dicho informe, la autoridad responsable manifestará, en principio, si es cierto o no lo que se reclama, esto es, si existe o no el acto tildado de inconstitucional, luego de manifestar que sí existe tal acto, dará las razones del porqué ello no violenta o trastoca los derechos fundamentales del quejoso, allegando copias certificadas de dicho acto para justificar sus asertos.

De igual forma, entre la fecha de notificación al quejoso del informe justificado y la de celebración de la audiencia constitucional, deberá mediar un plazo de por lo menos ocho días a fin de que el solicitante del amparo conozca el contenido del aludido informa y pueda manifestar lo que a sus intereses convenga; de lo contrario, se deberá acordar diferir o suspender el desahogo de tal audiencia, ya sea a solicitud del quejoso o del tercero interesado.

Llegado el día para la celebración de la audiencia, ésta deberá ser pública, donde se hará una relación de las constancias y pruebas desahogadas -es necesario puntualizar que en el amparo indirecto se reciben toda clase de pruebas, con excepción de la confesional, dado que la demanda se firma bajo protesta de decir verdad-, también se recibirán los alegatos por escrito que formulen las partes; luego, como acto continuo, se dictará la Sentencia pertinente.

Es preciso enfatizar, que la Ley de Amparo en su Artículo 124, al establecer "acto continuo se dictará el fallo que corresponda", debe entenderse que entre la celebración de la audiencia y el dictado de la Sentencia de amparo, no debe existir ninguna actuación en el juicio, ya que se rigen por el principio de indivisibilidad o unidad, de tal suerte que si el juzgador de amparo llegare a dictar un acuerdo entre ambas actuaciones, estaría trastocando el procedimiento del juicio de amparo.

Las Sentencias que se lleguen a dictar en el juicio de amparo indirecto, podrán ser de tres tipos a saber:

- $\quad$ Sobreseyendo en el juicio de amparo, al actualizarse alguna de las causales de sobreseimiento previstas en el Artículo 63 de la Ley de Amparo², incluidas las

2 Artículo 63.- El sobreseimiento en el juicio de amparo procede cuando:

I. El quejoso desista de la demanda o no la ratifique en los casos en que la ley establezca requerimiento. En caso de desistimiento se notificará personalmente al quejoso para que ratifique su escrito en un plazo de tres días, apercibido que de no hacerlo, se le tendrá por no desistido y se continuará el juicio. No obstante, cuando se reclamen actos que tengan o puedan tener como consecuencia privar de la propiedad o de la posesión y disfrute de sus tierras, aguas, pastos y montes a los ejidos o núcleos de población que de hecho o por derecho guarden el estado comunal, no procede el desistimiento del juicio o de los recursos, o el consentimiento expreso de los propios actos, salvo que lo acuerde expresamente la Asamblea General, pero uno y otro sí podrán decretarse en su beneficio. 
hipótesis de improcedencia.

- Negando el amparo solicitado, dado que es infundado lo alegado por el quejoso, derivado de que no resultó conculcatorio de derechos humanos el acto que se reclama.

- Concediendo el amparo solicitado, en razón de que el acto reclamado resultó violatorio de los derechos humanos del gobernado.

Ahora bien, por regla general, las Sentencias que se emitan en el juicio de amparo indirecto siempre serán impugnables a través del recurso de revisión, del que conocerá el superior jerárquico del Juez de Distrito: el Tribunal Colegiado de Circuito.

Recurso que deberá interponerse en el término de diez días ante el juez recurrido, contados a partir del día siguiente al en que surte efecto la notificación de la Sentencia que se dicte en el juicio de amparo indirecto.

De aquí que al juicio de amparo indirecto se le conozca como amparo bi-instancial, ya que implica la existencia de dos instancias.

Donde la Sentencia dictada por el Tribunal Colegiado de Circuito al calificar el recurso de revisión, en el sentido de confirmar, revocar o modificar el fallo recurrido, es inimpugnable.

También se considera necesario precisar -brevemente- que en el juicio de amparo indirecto se contempla a la figura de la suspensión del acto reclamado, cuya función es preservar la materia de este juicio constitucional, esto es, que no se ejecute el acto reclamado convirtiéndolo en consumado irreparablemente, mientras se analiza la constitucionalidad o no del acto reclamado, además deevitar que no se sigan violentando los derechos humanos del quejoso con la actuación tildada de inconstitucional. Esta figura resulta ser accesoria, pues pervive mientras subsista el juicio de amparo indirecto.

\section{PROCEDENCIA DEL JUICIO DE AMPARO DIRECTO}

Por su parte, el juicio de amparo directo o uni-instancial, conforme a lo dispuesto por el Artículo 179 de la Ley de Amparo, procederá en los siguientes supuestos a saber:

(I) Contra Sentencias definitivas, laudos o resoluciones que pongan fin al juicio, dictados por tribunales judiciales, administrativos, agrarios, o del trabajo, respecto de los cuales no procede ningún recurso ordinario por el que puedan ser modificados

II. El quejoso no acredite sin causa razonable a juicio del órgano jurisdiccional de amparo haber entregado los edictos para su publicación en términos del Artículo 27 de esta Ley una vez que se compruebe que se hizo el requerimiento al órgano que los decretó;

III. El q uejoso muera durante el juicio, si el acto reclamado sólo afecta a su persona.

IV. De las constancias de autos apareciere claramente demostrado que no existe el acto reclamado, o cuando no se probare su existencia en la audiencia constitucional; y

V. Durante el juicio se advierta o sobrevenga alguna de las causales de improcedencia a que se refiere el capítulo anterior. 
o revocados, ya sea que la violación a los derechos fundamentales se cometa en ellos, o que sea cometida durante el procedimiento y afecte a las defensas del quejoso, trascendiendo al resultado del fallo.

Significando que de estimar aspectos sobre inconstitucionalidad de normas generales que no sean de imposible reparación durante el juicio ordinario, sólo podrán hacerse valer en el amparo directo contra la Sentencia, laudo o resolución que le ponga fin al juicio.

(II) Contra Sentencias definitivas y resoluciones que pongan fin al juicio dictadas por tribunales de lo contencioso administrativo, cuando éstas sean favorables al impetrante del amparo, para el único efecto de hacer valer conceptos de violación en contra de las normas generales aplicables; lo anterior, sólo procede si la autoridad demandada en el juicio natural, interpone y se le admite el recurso de revisión a que alude el Artículo 104 de la Carta Magna, de tal suerte que dicho juicio de amparo, en este supuesto, resulta de carácter accesorio, pues el Tribunal Colegiado deberá resolver en la sesión correspondiente, en primer orden el recurso de revisión aludido, y de resultar fundado, analizará en segundo lugar, los conceptos de violación esgrimidos en el juicio de amparo directo, relativos a la constitucionalidad de la normas respectivas; y en caso contrario, esto es, de resultar infundado el recurso, será innecesario el examen de los conceptos de violación formulados en la demanda de amparo.

Es importante hacer notar, que tratándose de las violaciones que pueden cometer los tribunales responsables y que se deben de alegar en el juicio de amparo directo, son de tres tipos a saber:

- Violaciones procesales.

- Violaciones formales.

- Violaciones de fondo.

\section{Violaciones Procesales}

Las violaciones al procedimiento se encuentran contenidas en la propia Ley de Amparo, dividiéndose por razón de materia, toda vez que para la materia civil, administrativa y del trabajo es aplicable el Artículo 172, en tanto que las violaciones de índole penal se encuentran contenidas en el Artículo 173.

Es conveniente hacer notar que para que proceda el análisis de las violaciones procesales alegadas en amparo directo, entendiéndose como aquellas que se cometen durante la substanciación del juicio, deberán impugnarse en el curso mismo del procedimiento mediante la interposición oportuna del recurso ordinario o medio de defensa que establezca la ley que rige el acto.

Así, en el juicio de amparo directo puede hacerse valer como violación procesal al combatir la Sentencia, laudo o resolución definitiva, cualquier actuación durante el juicio que se estime resulte contraria a derecho, siempre que hubiese trascendido 
al sentido de ese fallo, afectando las defensas del quejoso.

En ese tenor, las hipótesis de violaciones al procedimiento y que afectan las defensas del quejoso, trascendiendo al resultado del fallo, en materia civil, administrativa, agraria, y laboral, son las siguientes:

a. Cuando al quejoso no se le cite a juicio, o se le cite en forma distinta de la prevenida por la ley. Esta situación estará condicionada a la existencia del incidente de nulidad intentado contra la ilegal notificación dentro del juicio natural, porque si el quejoso no compareció al juicio derivado de la ilegal notificación, entonces se surte la procedencia del amparo indirecto -tercero extraño a juicio o tercero extraño a juicio por equiparación-

b. Cuando el quejoso haya sido falsamente representado en el juicio que se trate.

c. Cuando se le desechen las pruebas que legalmente haya ofrecido, o cuando no se desahoguen conforme a la ley.

d. Cuando se declare ilegalmente confeso al quejoso, o a su representante o apoderado.

e. Cuando se deseche o se resuelva ilegalmente un incidente de nulidad.

f. Cuando no se le concedan los términos o prórrogas a que tuviere derecho con arreglo a la ley.

g. Cuando sin culpa del quejoso, se reciban, sin su consentimiento, las pruebas ofrecidas por las otras partes.

h. Cuando no se le muestren algunos documentos o piezas de autos, de manera que no pueda alegar sobre ellos, existiendo solicitud.

i. Cuando se le desechen los recursos a que tuviere derecho, con arreglo a la ley, respecto de providencias que afecten partes substanciales del procedimiento que produzcan indefensión.

j. Cuando se continúe el procedimiento, después de haber promovido una competencia o cuando el juez, magistrado o miembro de un tribunal del trabajo impedido o recusado, continúe conociendo del juicio.

k. Cuando se desarrolle una audiencia sin la presencia del juez o se practiquen diligencias judiciales de forma distinta a la prevenida por la norma.

1. En los demás casos análogos a los supuestos que preceden, a juicio de los órganos jurisdiccionales en materia de amparo directo.

Asimismo, las hipótesis de violaciones procesales con trascendencia en la esfera jurídica del quejoso, en materia penal, son las siguientes:

a. Que se desarrolle una audiencia sin la presencia del juez actuante o se practiquen diligencias en forma distinta a la prevenida por la ley.

b. Que el desahogo de las pruebas en el juicio de origen, se realicen por una persona distinta al juez que deba de intervenir. 
c. Que intervenga en el juicio penal un juez que haya conocido del caso previamente.

d. Que habiendo solicitado el desahogo del careo, no se practique en presencia del juez, en los supuestos y términos que prescribe la ley.

e. Que la presentación de argumentos y documentos en el juicio no se realicen de manera pública, contradictoria y oral.

f. Que la oportunidad para sostener la acusación o la defensa no se realice en igualdad de condiciones.

g. Cuando el juez reciba a una de las partes, para tratar el asunto sujeto a proceso, sin la presencia de la otra parte.

h. Cuando no se respete al imputado el derecho a declarar o guardar silencio, cuando la declaración del acusado se obtenga mediante incomunicación, intimidación, tortura o sin presencia de su defensor, o cuando el ejercicio del derecho a guardar silencio se utilice en su perjuicio.

i. Que el imputado no sea informado, desde el momento de su detención, en su comparecencia ante el Ministerio Público o ante el Juez, de los hechos que se le reprochan y los derechos que le asisten.

j. Cuando al acusado no se le reciban las pruebas que ofrezca o no se le reciban de acuerdo a lo que establece la ley, no se le conceda el tiempo para el ofrecimiento de pruebas, o no se le auxilie para obtener la comparecencia de las personas de quienes ofrezca su testimonio en los términos señalados por la ley.

k. Cuando el procesado no sea juzgado en audiencia pública por un juez o tribunal, salvo que se trate de los casos de excepción que establece la Constitución Federal.

1. Que no se le faciliten al imputado todos los datos que solicite para su defensa y que consten en el proceso o que se restrinja al imputado y a la defensa el acceso a los registros de investigación cuando el primero esté detenido o se pretenda recibirle declaración o entrevistarlo.

m. Cuando no se le respete al imputado el derecho a contar con una defensa adecuada por abogado que elija libremente desde el momento de su detención, o en caso de que no quiera o no pueda hacerlo, el juez no le nombre un defensor público, o cuando se impida, restrinja o intervenga la comunicación con su defensor; cuando el imputado siendo indígena no se le proporcione la asistencia de un defensor que tenga conocimiento de su lengua y cultura, así como cuando el defensor no comparezca a todos los actos del proceso.

n. En los casos de que el acusado no hable o entienda suficientemente el idioma español o sea sordo o mudo y no se le proporcione la asistencia de un intérprete que le permita acceder plenamente a la jurisdicción del Estado, o que tratándose de indígenas no se les proporcione un intérprete que tenga conocimiento de su lengua y cultura. 
o. Cuando no se le cite al imputado para las diligencias que tenga derecho a presenciar o se haga en forma contraria a la ley, y que por ello no comparezca, no se le admita en el acto de la diligencia o se le coarten en ella los derechos que la ley le otorga.

p. Cuando debiendo ser juzgado por un jurado, no se integre conforme a la ley o se le juzgue por otro tribunal.

q. Que se sometan a la decisión del jurado cuestiones de índole distintas a las señaladas por la ley.

r. Cuando no se permita interponer los recursos en los términos que la ley prevé respecto de actuaciones que afecten aspectos sustanciales del procedimiento y que produzcan indefensión.

s. Que siendo la víctima u ofendido, al dictarse la Sentencia definitiva o un auto que se refiera a la libertad del imputado, no se le hayan respetado los siguientes derechos: I). La asesoría jurídica y la información tanto de los derechos que le asisten como del desarrollo del procedimiento penal. II). Coadyuvar con el Ministerio Público, a fin de que se le reciban todos los datos o elementos de prueba con los que cuente tanto en la investigación como en el proceso y a que se le permita intervenir en el juicio. III). El resguardo de su identidad, cuando sean menores de edad o por delitos de violación, secuestro, delincuencia organizada o trata de personas y cuando a juicio del juzgador sea necesaria su protección, salvo que tal circunstancia derive de la debida salvaguarda de los derechos de la defensa. IV). Solicitar las medidas cautelares y providencias necesarias para la protección y restitución de sus derechos.

t. Cuando la Sentencia se apoye en alguna diligencia o actuación cuya nulidad haya sido establecida expresamente por una norma general.

u. Cuando seguido el proceso por el ilícito determinado en el auto de vinculación a proceso, el quejoso hubiese sido Sentenciado por diverso delito.

v. Cuando existan casos análogos a las hipótesis anteriores a juicio del Tribunal Colegiado de Circuito.

\section{Violaciones Formales}

Las violaciones formales son aquellas que se presentan en el dictado de la Sentencia, laudo o resolución que le puso fin al juicio, pero que no corresponden al análisis de fondo del negocio controvertido en el juicio de origen, esto es, son violaciones que únicamente atañen a aspectos de forma, como podría ser el que no se haya firmado la Sentencia por el juez o secretario del órgano jurisdiccional, el que no coincida lo dicho en los considerandos con lo precisado en los resolutivos de la Sentencia, el que no se hayan analizado todas las pruebas ofrecidas por algunas de las partes, o incluso el que se condene a una persona que no fue parte demandada en el juicio, entre otros. 


\section{Violaciones de Fondo}

Las violaciones de fondo se refieren a las infracciones que inciden en el análisis de la litis del asunto, esto es, en la esencia del conflicto que se dirime en el controvertido de origen, y que se actualizan dentro de la Sentencia, laudo o resolución que le pone fin al juicio, de tal suerte que esas transgresiones impactan en el examen que se haga sobre el fondo de la cuestión planteada en el juicio natural, y por ende, en el sentido del fallo, como por ejemplo, el relativo a la incorrecta o ilegal ponderación de pruebas dentro de la Sentencia reclamada y que conlleve a una condena o bien a la improcedencia de la acción.

Respecto de las violaciones mencionadas - procesales, formales y de fondo- es de significar que ello se le hará notar al juzgador de amparo, a través de los conceptos de violación que se esgriman o se formulen en la demanda de amparo, entendiendo por concepto de violación a los razonamientos lógico-jurídicos tendentes a evidencia la inconstitucionalidad del acto que se reclama.

\section{SUBSTANCIACIÓN DEL JUICIO DE AMPARO DIRECTO}

El juicio de amparo directo debe desahogarse en los términos que establece la propia Ley de Amparo, de la manera siguiente:

La demanda de amparo deberá presentarse por conducto de la autoridad responsable, dentro de los quince días siguientes a aquél en que surta efectos, conforme a la ley que rige al acto, la notificación al quejoso del acto reclamado.

Dentro del plazo de cinco días inmediatos contados al de la presentación de la demanda, la autoridad responsable deberá:

a. Certificar la data de presentación de la demanda de amparo, la fecha de notificación del acto reclamado, así como los días inhábiles que mediaron entre ambas fechas.

b. Conceder o negar la suspensión de plano en el auto de recepción de la demanda, en caso de solicitarse.

c. Correr traslado al tercero interesado para que comparezca al juicio.

d. Rendir el informe con justificación, acompañando la demanda de amparo, los autos del juicio natural, y las constancias del traslado a las partes.

Una vez presentado lo anterior ante el Tribunal Colegiado respectivo, debe recaer un auto dictado por el presidente del citado tribunal en el término de tres días, por el que admita, se declare incompetente, deseche por motivo manifiesto e indudable de improcedencia o bien mande aclarar la demanda por ser irregular, entre otros, lo anterior según la hipótesis que pudiera presentarse.

En caso de que el presidente del Tribunal Colegiado no hubiere encontrado un motivo manifiesto e indudable de improcedencia o defecto en el escrito inicial, o bien si éste fuere subsanado, además de ser competente, admitirá la demanda de 
amparo y ordenará notificar a las partes sobre ello, para que en el plazo de quince días comparezcan al juicio constitucional.

Transcurrido el plazo anterior, hayan o no comparecido las partes, el presidente del Tribunal Colegiado dentro del término de tres días siguientes, turnará el asunto al magistrado relator para que formule el proyecto de Sentencia dentro de los inmediatos noventa días; donde el auto de turno hace las veces de citación para el dictado de la Sentencia.

Formulado el proyecto de Sentencia, se deberá listar el asunto para que sea resuelto por el Pleno del Tribunal Colegiado de Circuito.

Luego de listado, se debe presentar por el magistrado relator a los demás integrantes del Tribunal el proyecto de Sentencia para su discusión en la sesión correspondiente, la cual será pública.

Los asuntos serán discutidos en el orden en que fueron listados, si el proyecto de Sentencia fuese aprobado por el Pleno del Tribunal, se firmará para constituir Sentencia dentro de los diez días siguientes.

En el supuesto de que no fuera aprobado el proyecto, se podrá retirar o aplazar, debiéndose listar nuevamente en un plazo no mayor de treinta días naturales.

$\mathrm{Si}$ el asunto fuera aprobado por la mayoría en sentido distinto al del proyecto, se designará a otro magistrado relator de entre los de la mayoría, quien tendrá diez días para dictar Sentencia.

La Sentencia que se dicte, deberá ser firmada por todos los magistrados y por el secretario de acuerdos, para luego ser notificada a las partes.

De igual forma que en las Sentencias dictadas en el juicio de amparo indirecto, los alcances de la Sentencia en el amparo directo, son distintos.

Ciertamente, si la Sentencia que se llegare a dictar es de sobreseimiento, por actualizarse alguna hipótesis prevista en el Artículo 63 de la Ley de Amparo, el fallo que se dicte le pone fin al juicio, lo que impide emitir consideraciones sobre la constitucionalidad o inconstitucionalidad del acto reclamado, dejando así el acto reclamado en las mismas condiciones en que se encontraba antes de la presentación de la demanda de amparo.

Por el contrario, si la Sentencia de amparo se dicta en el sentido de que se niegue la protección de la justicia federal, porque el acto que se reclama no resulta conculcatorio o violatorio de los derechos fundamentales del gobernado, esto es, que dicho acto se dictó con apego a lo que demarca la parte dogmática de la Constitución Federal, tiene como particularidades finalizar el juicio de amparoy declarar la constitucionalidad del acto que se reclama, por lo que se deja a tal acto en las mismas condiciones en que se encontraba antes de promoverse el juicio de amparo.

Y si la Sentencia que se emite es en el sentido de que se concede la protección de la justicia federal solicitada, debido a que el acto reclamado resulta violatorio de los derechos humanos, esto es, que el actuar de la autoridad responsable resultó transgresor de la esfera jurídica del gobernado en sus derechos esenciales, dicho 
fallo constitucional presenta como alcances el declarar la inconstitucionalidad del acto reclamado, dejar insubsistente la Sentencia, laudo o resolución que le pone fin al juicio, y ordenar que se dicte un nuevo fallo en el que se repare al quejoso del derecho humano violentado.

Si se ha concedido la protección de la justicia federal por una violación procesal, el efecto de la ejecutoria de amparo consistirá en dejar insubsistente la Sentencia reclamada y ordenar reponer el procedimiento para que se purgue la violación procedimental, y hecho ello, deberá dictarse una nueva Sentencia con libertad de jurisdicción.

Y dependiendo de tales alcances es que el amparo otorgado será: a) liso y llano, o bien, b) para efectos.

El primer supuesto (el amparo liso y llano) tratándose del juicio de amparo uni-instancial, se actualiza cuando el tribunal de amparo otorga la protección de la justicia federal de manera total, esto es, cuando -frente a la violación de los derechos esenciales del quejoso- se ordena a la responsable dejar insubsistente el acto reclamado, y dictar uno nuevo donde resuelva favoreciendo en todo respecto de las pretensiones del impetrante del amparo en el controvertido de origen; lo que implica que se decida en definitiva el fondo del negocio, y por ende, a la improcedencia de posteriores juicios de amparo directo promovidos por cualquiera de las partes.

Por su parte, el segundo supuesto (el amparo para efectos), es cuando el tribunal de amparo en su Sentencia ordena a la autoridad responsable que desarrolle determinadas conductas mediante las cuales subsane o purgue las violaciones que haya cometido durante la substanciación del procedimiento o bien en el dictado de su resolución o fallo con el que le puso fin al juicio, dejándole libertad de jurisdicción para que -cuando dicte la nueva Sentencia- resuelva conforme a derecho proceda, por lo que, en este caso, la responsable queda vinculada a realizar uno o varios actos restauradores de los derechos humanos afectados, teniendo libertad para decidir sobre el fondo de la litis planteada en el sumario natural; lo cual da pauta a que posteriormente se promuevan nuevos juicios de amparo directo.

Es de significar que las Sentencias dictada en amparo directo -por regla generalson inimpugnables, razón por la que se le conoce al juicio de amparo directo como uni-instancial, derivado precisamente de que dicha Sentencia no puede ser combatida, y por tanto, los Tribunales Colegiado de Circuito que conocen del referido juicio de amparo directo, son órganos jurisdiccionales terminales.

Asimismo, en el juicio de amparo directo o uni-instancial, se prevé la procedencia de la suspensión del acto reclamado, cuyo efecto será que se mantengan las cosas en el estado en que se encuentran, esto es, que no se ejecute la Sentencia, laudo o resolución que le pone fin al juicio, hasta en tanto se resuelve el fondo del juicio de amparo. 


\section{CUMPLIMIENTO DE LAS SENTENCIAS DE AMPARO}

La realización pragmática de los efectos de una Sentencia concesoria de amparo indirecto o directo, engendra deberes que ha de acatar la autoridad o autoridades responsables, de conformidad con lo dispuesto por el Artículo 77 de la Ley de Amparo.

De este modo, cuando el acto reclamado es de carácter positivo, esto es, cuando la conducta o el hacer de la autoridad responsable afectan la esfera del gobernado, el objeto de la Sentencia protectora consistirá en la restitución al quejoso en el pleno goce de la garantía violada, restableciendo las cosas al estado que guardaban antes de la violación.

En la hipótesis de que el acto tachado de inconstitucional sea de índole negativa, es decir, derivado de una abstención o un no hacer de la autoridad, el alcance del amparo consistirá en obligar a la autoridad responsable a que acate y respete los derechos fundamentales violados; de esta forma, el amparo concedido tendrá como efecto que la autoridad actúe respetando este derecho.

Atento a ello, deberá tenerse presente que tratándose del juicio de amparo directo, cuando se otorga la protección de la justicia federal en contra de una Sentencia o laudo, por irregularidades procesales o formales, o bien cuando habiéndose estudiado el fondo de la controversia se hayan definido todas las cuestiones debatidas, el cumplimiento del fallo protector consistirá, en esencia, en dejar sin efectos la resolución jurisdiccional reclamada y emitir otra en la que se atienda a la Sentencia amparadora.

Asimismo, el órgano de amparo deberá vigilar su cumplimiento, sin que pueda acordar el archivo del expediente mientras aquel no ocurra.

$\mathrm{Y}$ en caso de que se considere que la autoridad responsable no cumpla cabalmente con lo ordenado por el órgano jurisdiccional de amparo, la propia Ley de Amparo prevé diversos mecanismos para alcanzar su cumplimiento, como lo es: el incidente de inejecución de Sentencia, el incidente de repetición del acto reclamado, o bien, la inconformidad.

Además de que la autoridad responsable -por no acatar en sus términos la Sentencia de amparo, o bien, existir una abstención total en su cumplimiento- será sancionada con la separación del cargo que ostenta y se le procesará penalmente por el delito de incumplimiento a una Sentencia de amparo, cuya penalidad oscila de cinco a diez años de prisión.

\section{REFORMA A LA LEY DE AMPARO}

Expuesto lo anterior, es de establecer que dentro de las reformas a la Ley Reglamentaria de los Artículos 103 y 107 de la Constitución Federal ${ }^{3}$, se encuentra la

3 Publicada en el Diario Oficial de la Federación el 2 de abril de 2013. 
relativa al amparo adhesivo.

Ciertamente el Artículo 182 de la Ley de Amparo en vigor, prevé el amparo adhesivo a fin de observar la tutela judicial efectiva, dado que con tal figura se pretende disminuir de las Sentencias de amparo, el llamado "amparo para efectos".

Lo anterior, debido a que las Sentencias que se dictan para efectos implican que se deje a la autoridad responsable con libertad de jurisdicción para que, una vez que repare la violación a los derechos humanos del gobernado, dicte una nueva resolución misma que puede ahora resultar desfavorable para la contraparte que haya obtenido inicialmente un fallo favorable a sus intereses.

En ese sentido, al promover el amparo contra esa nueva determinación, la parte interesada puede combatir las violaciones procesales que, desde su óptica, se hubieran cometido en su contra durante el proceso original, en cuyo caso, de resultar fundadas dichas alegaciones, se concederá el amparo para el efecto de que la responsable reponga el procedimiento con el fin de que se purgue tal violación procedimental, y una vez hecho ello, deberá dictar nuevamente una Sentencia con libertad de jurisdicción, misma que de resultar desfavorable puede ser combatida mediante un nuevo juicio de amparo directo, donde en la demanda que al efecto se formule, también se podrán plantear conceptos de violación encaminados a controvertir aspectos procesales, que pueden dar lugar a un nuevo amparo para efectos que conlleve a la reposición del procedimiento, y así sucesivamente, por lo que, en ese sentido el controvertido que dio origen a todos estos juicios de amparo directo puede implicar muchos años, retrasándose con ello la solución que finalmente decida el fondo del negocio en perjuicio de las partes y afectando su seguridad jurídica, así como la finalidad de la justicia que debe ser pronta y expedita, evento que se traduce en una inobservancia a la tutela judicial efectiva.

Como una solución a lo anterior, se implementa ahora en la Ley de Amparo la figura del amparo adhesivo, a fin de que todas las violaciones acaecidas durante el juicio, esto es, violaciones procesales, formales y de fondo, se resuelvan en una sola Sentencia de amparo, decidiéndose así integralmente la problemática del amparo planteada, a fin de evitar mayores dilaciones, en detrimento de la tutela judicial efectiva.

Significando que en el instante en que alguna de las partes (actor o demandado en el juicio de origen), impugne la Sentencia definitiva que se dicta en el controvertido natural, mediante el juicio de amparo con la que la otra se había conformado, poniendo en peligro lo ganado, nace el derecho de esta última para interponer el amparo adhesivo y hacer valer, a través de ello conceptos de violación, que deben versar sobre tres premisas:

I. Violaciones ocurridas durante el desahogo del procedimiento en perjuicio del adherente, pero que finalmente no trascendieron dado que el fallo definitivo le fue favorable.

II. Violaciones ocurridas en la Sentenciasobre aspectos que le perjudican al que promueve dicha adhesión, pero que guardan relación con la parte resolutiva 
que le favorece y que, como consecuencia del amparo directo principal, pueden trascender en su perjuicio.

III. Ciertamente, la parte que en el juicio obtuvo Sentencia favorable puede adherirse al amparo principal si estima qe la misma contiene consideraciones contrarias a sus intereses, empero que no repercutieron en la conclusión del fallo emitido por la autoridad responsable, ya que le benefició a fin de que si se tuvieran por fundados los conceptos de violación esgrimidos por el quejoso en el amparo principal, den base al Tribunal Colegiado para examinar la totalidad de la cuestión planteada en el controvertido de origen.

IV. Esgrimir alegaciones orientadas a robustecer las consideraciones de la Sentencia que le favorezcan, esto es, hacerle notar al Tribunal Colegiado que las causas que motivaron a la autoridad responsable para haber arribado a su determinación resultan objetivamente correctas, soportando lo decidido por la responsable o bien, el argumentar más lo expuesto por ésta, al advertir que la Sentencia reclamada descansa en argumentos débiles o en razonamientos poco convincentes o mal expresados, cuando en realidad existen otros más sólidos y de mayor fuerza persuasiva.

Todo esto, con el propósito de que no se conceda el amparo principal y dejar sin efectos aquello que le beneficia a quien promueve el amparo adhesivo.

Además, se estima conveniente hacer notar que esta nueva Ley de Amparo, respecto del amparo adhesivo previsto en el Artículo 182 transcrito, implica que el tercero interesado -adherente- deba conocer apropiadamente esta figura jurídica de la adhesión y sus implicaciones, ya que de lo contrario, corre el riesgo de que si no se adhiere al amparo principal, formulando conceptos de violación encaminados a evidenciar violaciones procesales acaecidas en su perjuicio y que pudieran trascender al resultado del fallo, así como violaciones que se relacionan con un punto decisorio que le perjudica, pero que guardan relación con la parte resolutiva que le fue favorable, conlleva a que ya no podrán hacerse valer en un segundo amparo interpuesto en contra de la Sentencia que -en su caso- se dictara en cumplimiento al primer amparo intentado por el colitigante, al estimarse consentidas a tales violaciones por no haberse impugnado a través del amparo adhesivo en el momento procesal oportuno, extremo que robustece el hecho de que solamente exista un juicio de amparo y no una proliferación de estos juicios constitucionales, derivado de las Sentencias dictadas "para efectos".

\section{SUBSTANCIACIÓN DEL AMPARO ADHESIVO}

El trámite para el desahogo del amparo adhesivo se regirá por lo determinado en la Ley Reglamentaria de los Artículos 103 y 107 de la Constitución Federal, en el acápite relativo a la substanciación del amparo directo, por tanto, una vez admitida la demanda de amparo principal formulada por el quejoso, el Tribunal Colegiado mandará notificar a las partes (autoridad responsable, Ministerio Público Federal y 
tercero interesado) del acuerdo relativo, para que en el plazo de quince días presenten sus manifestaciones, o bien, el tercero interesado promueva amparo adhesivo, donde la notificación a este último deberá ser de carácter personal por ser la primera notificación en el juicio constitucional y además, por las consecuencias que implica en el amparo adhesivo- el no esgrimir argumentos tendentes a evidenciar violaciones procesales o puntos decisorios en la Sentencia que le perjudican, pero que tienen relación directa con la parte resolutiva que le beneficia.

Luego, una vez admitido el escrito de adhesión, el Tribunal Colegiado de Circuito ordenará notificar sobre ello a la parte quejosa, a fin de que formule sus alegatos correspondientes.

Transcurrido el término de quince días otorgado para que se promueva el amparo adhesivo, dentro de los tres días siguientes, se turnará el expediente que contenga tanto la demanda de amparo principal como la demanda de amparo adhesivo, al magistrado ponente para que formule el proyecto de Sentencia dentro de los noventa días siguientes, en el que se tendrá que analizar integralmente tanto los conceptos de violación planteados en la demanda de amparo principal como los conceptos de violación formulados en la demanda de amparo adhesivo.

Terminado el proyecto de Sentencia, se listará el asunto en los estrados del Tribunal Colegiado de Circuito, señalándose fecha para que se resuelva en una sesión por el Pleno del Tribunal Colegiado (la lista deberá publicarse cuando menos tres días antes de celebrarse la sesión), para lo cual el magistrado relator circulará con los otros dos magistrados una copia de su propuesta de Sentencia, para que en el día de la sesión discutan tanto lo esgrimido en la demanda principal como lo alegado en la adhesión, quedando los autos a su disposición para su estudio en la secretaría del órgano jurisdiccional.

Posteriormente, una vez desahogada la sesión y decidido por los integrantes del Tribunal Colegiado el sentido del asunto, en el que se haya calificado tanto lo aducido en la demanda de amparo principal como en el amparo adhesivo, el secretario de acuerdos lo publicará en la lista correspondiente, donde la determinación de dicho órgano jurisdiccional -por regla general- será inimpugnable.

No debe perderse de vista que la figura del amparo adhesivo es accesoria, pues de lo que se decida en el amparo directo principal, seguirá la misma suerte procesal el amparo adhesivo, esto es, solamente cuando los conceptos de violación formulados por el quejoso en el amparo directo principal sean fundados, debe existir pronunciamiento y análisis sobre los conceptos de violación expuestos por quien se adhiere al amparo, o bien, si los conceptos de violación formulados en el amparo principal resultan ser infundados, y por ello, no procede conceder el amparo solicitado respecto del acto reclamado que resultó favorable al adherente del juicio constitucional, desaparece la condición procesal a que se halla sujeto el interés jurídico para estudiar las inconformidades planteadas en el amparo adhesivo, al encontrarse -con ello- satisfecha su finalidad. 
En corolario, se estima que la implementación del amparo adhesivo en el marco jurídico mexicano resulta eficaz para la observancia del Artículo 17 de la Carta Magna ${ }^{4}$, dado que la idea de resolver en un único juicio de amparo todas las violaciones procesales, formales y de fondo planteadas por ambas partes -actor y demandado- en el controvertido de origen, permitirá que los órganos jurisdiccionales especializados en la materia del juicio de amparo estén en posibilidad de resolver en una sola Sentencia toda la controversia de origen de manera definitiva, con lo cual se obtendrá una mejor administración de justicia al evitar dilaciones en la solución de los procedimientos ordinarios, extremo que se traduce -finalmente- en una tutela judicial efectiva.

Otra de las innovaciones que se presenta con la nueva Ley de Amparo, consiste en la implementación de más causales de improcedencia-de las dieciocho ya existentes-, extremo que hace más riguroso al juicio de amparo en cuanto a su procedencia;lo anterior sin perder de vista que las hipótesis que dan lugar a la improcedencia del juicio de amparo, deben de identificarse con los presupuestos procesales que en todo juicio tienen que satisfacerse, como así lo destaca Noriega Cantú (2000).

Ciertamente, en cualquier juicio es indispensable para que pueda desahogarse y en su momento exista una Sentencia que decida el fondo de la controversia planteada, el que se satisfagan los presupuestos procesales, ya que de no ser así, esto es, el que no se cumplan con dichos presupuestos, dará lugar a que el juicio de que se trate no prospere, por ejemplo, en un juicio civil tenemos como presupuesto procesal para que el juez pueda pronunciarse respecto al fondo de la litis planteada, a la competencia, la personalidad, la litis consorcio pasivo necesario, entre otros.

Así pues, de no satisfacerse los presupuestos procesales en el juicio de amparo, ello conlleva a que tal institución jurídica sea improcedente, evento que implicael que no se analice si el acto que se reclama resulta ser violatorio o no de los derechos humanos del quejoso.

En ese tenor, las causales de improcedencia no deben de considerarse como pretexto para que el juzgador especializado en la materia de amparo, deje de analizar la constitucionalidad del acto que se reclama, sino todo lo contrario, las causales de improcedencia hacen que el juicio de amparo sea más técnico por cuanto a su procedencia, y en esa tecnicidad va implícito el que esta institución sea realmente formal y seria, es decir, que su accionar o práctica por parte del gobernado tenga cabida sólo cuando verdaderamente se justifique su procedencia a fin de cumplir con la naturaleza del juicio de amparo.

De esta forma, se evita la substanciación innecesaria de juicios de amparoy el análisis de fondo, por no satisfacerse los presupuestos para su procedencia, como

4 Artículo 17. Toda persona tiene derecho a que se le administre justicia por tribunales que estarán expeditos para impartirla en los plazos y términos que fijen las leyes, emitiendo sus resoluciones de manera pronta, completa e imparcial. Su servicio será gratuito, quedando, en consecuencia, prohibidas las costas judiciales. 
acontece en otros juicios, ya sea civil, laboral, administrativo, entre otros.

La apariencia del buen derecho es otra de las figuras que se insertan en la nueva Ley de Amparo en su Artículo 138, la cual resulta ser un presupuesto para poder darle curso a la medida cautelar -suspensión del acto reclamado-, descansando ello en una convicción objetiva que elimine toda posibilidad de intención infundada con su promoción, extremo que se logra a través de un examen superficial o provisional del derecho cuestionado a fin de poder arribar a un decisión de mera probabilidad, con el propósito de otorgar tal medida cautelar a fin de evitar daños y perjuicios de difícil reparación al quejoso y así mantener viva la materia del juicio de amparo, respecto del acto arbitrario de la autoridad responsable.

Consecuentemente, el órgano jurisdiccional especializado en la materia de amparo, cuando se pronuncie sobre la suspensión solicitada del acto que el quejoso estime violentó sus derechos humanos, deberá realizar un análisis ponderando la apariencia del buen derecho, en los términos indicados.

De igual forma, ahora se prevé en la Ley de Amparo el interés legítimo como presupuesto para instar la acción de amparo, únicamente tratándose de actos administrativos, es decir, respecto de actos emitidos por autoridades estrictamente administrativas que trastoquen los derechos fundamentales del gobernado, donde sólo se requiere, para que proceda el juicio de amparo bi-instancial, que la afectación en la esfera jurídica del quejoso sea indirecta y no directa, misma que puede ser de naturaleza económica, profesional, de salud pública, educación, entre otros.

Para arribar a lo anterior, es de precisar que existen tres categorías de intereses, que se hacen consistir en:

Interés jurídico, mismo que tendrá el quejoso cuando la violación en sus derechos fundamentales sea personal y directa, donde de concedérsele el amparo solicitado, obtendrá el beneficio de que se le repare de la violación a su esfera jurídica en sentido estricto.

Interés legítimo que el solicitante del amparo podrá ostentar cuando la afectación en sus derechos fundamentales sea indirecta y que de concedérsele el amparo, obtendría el beneficio de que se le repare indirectamente en sus derechos esenciales, esto es, un beneficio jurídico a su favor derivado de una afectación en su esfera jurídica en sentido amplio.

Mientras que el interés simple, que puede tener cualquier persona frente al actuar del Estado, no cuenta con la anterior tutela que posee el interés simple como el interés legítimo, en tanto que la ley o el acto que reclama no le causa agravio jurídico, es decir, de satisfacerse la pretensión -bajo el esquema del interés simple- no se traduciría en un beneficio personal para el interesado, ya que no supone una afectación a su esfera jurídica en algún sentido, lo que conlleva a que el interés simple no tenga lugar en el juicio de amparo.

Por ende, si ahora el quejoso promueve un juicio de amparo contra actos administrativos alegando un interés legítimo, por trastocarse un derecho difuso en 
perjuicio de una colectividad, al cual demuestra que pertenece, el juez de amparo deberá darle curso y resolver en consecuencia si efectivamente tal acto resultó inconstitucional.

Asimismo, fueron aumentadas las hipótesis de suplir la deficiencia de la queja, contempladas en el Artículo 79 de la Ley de Amparo ${ }^{5}$, significando respecto de ellas una en particular, consistente en que operara tal beneficio en cualquier materia, a favor de quienes por sus condiciones de pobreza y marginación se encuentren en clara desventaja social para su defensa en el juicio; lo cual implica que dicha institución será procedente en materias de estricto derecho como la fiscal, civil, o mercantil, siempre y cuando se acredite tal extremo en el juicio de amparo, ello a fin de acercar la justicia a la clase económicamente débil.

Con esta nueva hipótesis se trastoca el principio rector del juicio de amparo relativo al estricto derecho, el cual exige que el juez se limite a resolver los actos reclamados y los conceptos de violación que se expresan en la demanda, sin hacer consideraciones de inconstitucionalidad o ilegalidad que no hayan sido invocadas por el agraviado, esto es, en la medida en que se esgriman conceptos de violación

5 Artículo 79. La autoridad que conozca del juicio de amparo deberá suplir la deficiencia de los conceptos de violación o agravios, en los casos siguientes:

I. En cualquier materia, cuando el acto reclamado se funde en normas generales que han sido consideradas inconstitucionales por la jurisprudencia de la Suprema Corte de Justicia de la Nación y de los Plenos de Circuito. La jurisprudencia de los Plenos de Circuito sólo obligará a suplir la deficiencia de los conceptos de violación o agravios a los juzgados y tribunales del circuito correspondientes.

II. En favor de los menores o incapaces, o en aquellos casos en que se afecte el orden y desarrollo de la familia.

III. En materia penal:

a. En favor del inculpado o Sentenciado; y

b. En favor del ofendido o víctima en los casos en que tenga el carácter de quejoso o adherente.

IV. En materia agraria:

a. En los casos a que se refiere la fracción III del Artículo 17 de esta Ley;

b. En favor de los ejidatarios y comuneros en particular, cuando el acto reclamado afecte sus bienes o derechos agrarios.

En estos casos deberá suplirse la deficiencia de la queja y la de exposiciones, comparecencias y alegatos, así como en los recursos que los mismos interpongan con motivo de dichos juicios.

V. En materia laboral, en favor del trabajador, con independencia de que la relación entre empleador y empleado esté regulada por el derecho laboral o por el derecho administrativo;

VI. En otras materias, cuando se advierta que ha habido en contra del quejoso o del particular recurrente una violación evidente de la ley que lo haya dejado sin defensa por afectar los derechos previstos en el Artículo 1 de esta Ley. En este caso la suplencia sólo operará en lo que se refiere a la controversia en el amparo, sin poder afectar situaciones procesales resueltas en el procedimiento en el que se dictó la resolución reclamada;

VII. En cualquier materia, en favor de quienes por sus condiciones de pobreza o marginación se encuentren en clara desventaja social para su defensa en el juicio.

En los casos de las fracciones I, II, III, IV, V y VII de este Artículo la suplencia se dará aún ante la ausencia de conceptos de violación o agravios.

La suplencia de la queja por violaciones procesales o formales sólo podrá operar cuando se advierta que en el acto reclamado no existe algún vicio de fondo. 
formulados contra el acto que se reclame, es como se realizará el examen de su constitucionalidad o inconstitucionalidad.

Por tanto, aún y cuando el tribunal de amparo llegare a advertir alguna violación en los derechos humanos del quejoso, si éste no lo combatió a través de los conceptos de violación planteados en el escrito de demanda, el órgano jurisdiccional de amparo no analizará dicha violación.

Con base en este principio, entonces los tribunales de amparo no están facultados para apreciar con libertad los posibles aspectos inconstitucionales del acto o la ley que se reclama en la vía constitucional, sino que están obligados solamente a analizar los que se plantean en la demanda de amparo; sin poder subsanar las omisiones o suplir las deficiencias en que haya incurrido el quejoso al formular la misma.

Sin embargo, con la figura de la suplencia de la deficiencia de la queja como excepción al principio de estricto derecho, que consiste en que aún ante la falta de inconformidad, el órgano jurisdiccional de amparo debe analizar oficiosamente cualquier aspecto que evidencie la inconstitucionalidad del acto o resolución que se reclama, generalmente, a efecto de otorgar al quejoso la protección de la justicia federal, en aras de proteger a los grupos de la sociedad que se encuentran más vulnerables, únicamente operaba en supuestos muy específicos, ahora con la nueva hipótesis en mención, procederá la suplencia de la deficiencia de la queja en cualquier supuesto y en cualquier materia -aún de estricto derecho- siempre y cuando el quejoso acredite ubicarse en un estado de pobreza y marginación, evento que obedece a un nuevo paradigmacon pretensión de ayudar a la sociedad en México que se encuentre desprotegida por falta de recursos económicas, esto es, para que se tenga acceso a un mecanismo que tutele los derecho humanos de manera efectiva, sin que ello se obstruya por meros tecnicismos.

Así pues, son diversas las figuras que ahora se insertan en el juicio de amparo a través de una nueva ley y muchas otras ya existentes que siguen permeando, lo que indudablemente permitirá que este medio de control constitucional pueda alcanzar a cabalidad su fin deseado, que consiste en proteger de manera eficaz los derechos humanos frente a los actos de la autoridad, intención queha sido desde que se gestó en el Estado de Yucatán, México en el año de 1841, con don Manuel Crescencio Rejón considerado el padre del amparo, como lo sostienen Soberanes, J. L. y Martínez, F. J. (2010).

Lo anterior, sin perder de vista que para materializar la eficacia aludida, es necesario queesta institución del amparo sea competencia de órganos jurisdiccionales especializados y se desahogue como un juicio, donde existe un actor (quejoso), un demandado (autoridad responsable), una litis, pruebas, alegatos y Sentencia, ello a fin de darle la trascendencia o fuerza necesaria para limitar el poder del Estado cuando resulte transgresor de los derechos esenciales de la persona.

En este orden de ideas, si el Estado de Derecho implica, entre otras cosas, que exista justicia, y en México el juicio de amparo es el medio -por excelenciapara proteger al gobernado de todo acto de autoridad que violente sus derechos 
fundamentales, con las reformas ahora mencionadas que pretenden perfeccionar a tal institución, obvio es que bajo este esquema, el amparo resulte ser un verdadero garante del Estado de Derecho en México.

\section{REFERENCIAS}

Dirección General de Estadística Judicial del Consejo de la Judicatura Federal. (2013).

Órganos Jurisdiccionales. Consultado en septiembre 20 de 2013. Disponible en: http://www.dgepj.cjf.gob.mx.

Noriega, A. (2000). Lecciones de amparo, $6^{\mathrm{a}}$ ed. México: Porrúa.

Soberanes, J. L.; y Martínez, F. J. (2010). Apuntes para la historia del juicio de amparo. México: Porrúa. 
